\title{
Patient experience in long-term conditions: revealing invisible perspectives
}

Chronic diseases, their management and prevention continue to be a major preoccupation of policymakers, primary care researchers and clinicians alike. Globally, non-communicable diseases such as cardiovascular disease and diabetes account for approximately 35 million deaths annually and are nearly all preventable as causes of premature death (World Health Organization, 2008). The recent For World No Tobacco Day, May $31^{\text {st }}$ 2011, exemplifies the current battle being fought to challenge lifestyles and promote healthier living; however, there is a long way to go to curb the ever-increasing number of people who are living with one or more long-term conditions. Therefore, in tandem with preventative strategies, there is a concurrent emphasis on service design and the implementation of models of chronic disease management. In the United Kingdom, the Long-Term Conditions Health and Social Care framework (Department of Health, 2005) is broadly modelled on the Chronic Care Model (Bodenheimer et al., 2002), and envisages optimum chronic disease management being operated through an integrated system supported by effective data systems, with proactive health and social care professionals and informed and empowered patients.

Nevertheless, however well designed a model may be, it is still one that is often imposed on the individual patient and may fail to be sensitive enough to adapt to the actual experience of living with a long-term condition. Although there is no doubt that there is an intention to facilitate empowered patients, this often becomes tied up in a world of paradigmatic tension. Two qualitative evaluations of the UK Expert Patients Programme (EPP) illustrated these tensions. On the basis of the Chronic Disease Self-Management Programme (Lorig et al., 2001), the generic EPP follows an often bio-medicalised approach to selfmanagement, but by the very nature of being in a small group of peers this is often contested by the acknowledgement of the unique subjective experience (Wilson et al., 2007). A modified EPP

(C) Cambridge University Press 2011 for people with moderate intellectual disabilities also uncovered a polarised viewpoint on the aim and desired product of such programmes; health behaviour changes versus social outcomes such as increased social engagement (Wilson and Goodman, in press).

Trying to capture the patient experience in longterm conditions is challenging, and reliance on surveys and tick boxes often fails to capture the full essence of what is going on (Patient Opinion, 2011). Organisations such as HealthTalk Online (http://www.healthtalkonline.org/) are beginning to build up evidence on patient experience through individuals' own narratives, but there is still a dearth of work in this area. Morris et al.'s (2011) qualitative study on patient experience of selfmanaging co-morbidities is one of a few studies to move beyond a focus on a single long-term condition. The findings suggest that prioritisation of self-management in an individual with one or more chronic diseases is complex and often undertaken at an intuitive level, applying lessons learnt from one condition to another. It also highlighted clinicians' preoccupation with dealing with the health conditions individually, rather than the patient as a whole. Exploring chronic disease management through the patient perspective also leads to some unexpected findings. For example, an emerging finding from a UK study we are currently undertaking on patient experience of longterm conditions suggests that rather than talking in terms of integration and coordination, patients are more preoccupied with how services reduce their workload of managing a long-term condition on a day-to-day basis. This illustrates the need to reduce the effort required in maintaining the balance between the trajectory (self-management) work and biographical (self-identity) work (Charmaz, 1983; Corbin and Strauss, 1985). One of the most frequently mentioned sources of trajectory work in our study is the work involved in organising a repeat prescription; a workload increased substantially when prescriptions were limited to a 
month's supply, multiple medications were not synchronised in terms of when they would need to be ordered, and pharmacists failing to have the medications in stock. Although the evidence on repeat prescribing and dispensing often focuses on medicine waste (Trueman et al., 2010), there is less in-depth evidence on the experience for individuals in ordering, collecting and dealing with any issues in the system, which potentially has significant implications for the way repeat dispensing is organised in stable long-term conditions.

In conclusion, there is a growing body of primary care research evaluating interventions and systems restructuring within chronic disease management. However, if there is not an equal focus on patient experience, then we miss the opportunity to illuminate aspects of chronic disease models and interventions previously invisible. Patient experience is where the whole system of health and social care is embodied in the experience of each individual patient (Kendall et al., 2010).

\section{Patricia Wilson \\ Email:p.m.wilson@herts.ac.uk}

\section{References}

Bodenheimer, T., Wagner, E.H. and Grumbach, K. 2002: Improving primary care for patients with chronic illness. The Chronic Care Model, Part 2. Journal of the American Medical Association 288, 1909-13.

Charmaz, K. 1983: Loss of self: a fundamental form of suffering in the chronically ill. Sociology of Health \& Illness 5, 168-95.

Corbin, J. and Strauss, A. 1985: Managing chronic illness at home: three lines of work. Qualitative Sociology 8, 224-47.
Department of Health. 2005: Supporting people with long term conditions. An NHS and Social Care Model to support local innovation and integration. London: Department of Health.

Kendall, S., Wilson, P.M., Brooks, F., Procter, S., and Bunn, F. 2010: Evaluating the nursing contribution to models of chronic disease management: a whole systems approach. National Institute of Health Research, http://www. sdo.nihr.ac.uk/projdetails.php?ref $=08-1605-121$

Lorig, K.R., Sobel, D.S., Ritter, P.L., Laurent, D. and Hobbs, M. 2001: Effect of a self-management program on patients with chronic disease. Effective Clinical Practice 4, 256-62.

Morris, R.L., Sanders, C., Kennedy, A.P. and Rogers, A. 2011: Shifting priorities in multimorbidity: a longitudinal qualitative study of patient's prioritization of multiple conditions. Chronic Illness 7, 147-61.

Patient Opinion. 2011: In their words. What patients think about our NHS. Retrieved 1 May 2011 from http:// www.patientopinion.org.uk/resources/POreport2011.pdf

Trueman, P., Lowson, K., Blighe, A., Meszaros, A., Wright, D., Glanville, J., Taylor, D., Newbould, J., Bury, M., Barber, N., and Jani, Y. 2010: Evaluation of the scale, causes and costs of waste medicines. York Health Economics Consortium and School of Pharmacy, University of London. Retrieved 17 June 2011 from http:/www.pharmacy.ac.uk/fileadmin/ documents/News/Evaluation_of_NHS_Medicines_Waste web_publication_version.pdf

Wilson, P.M., and Goodman, C. (in press): Evaluation of a modified chronic disease self-management programme for people with intellectual disabilities. Journal of Nursing and Healthcare of Chronic Illness.

Wilson, P.M., Kendall, S. and Brooks, F. 2007: The Expert Patients Programme: a paradox of patient empowerment and medical dominance. Health and Social Care in the Community 15, 426-38.

World Health Organization. 2008: 2008-2013 action plan for the global strategy for the prevention and control of noncommunicable diseases. Geneva: World Health Organization. 